\title{
Chouati, Yassine.
}

Profesor Contratado Predoctoral VI Plan Propio, Universidad de Sevilla, Departamento de Dibujo, grupo Gráfica y Creación Digital.

\section{El registro gráfico en la obra del artista árabe expatriado en}

\section{Europa: recursos y narrativas}

\section{The graphic record in the work of the expatriate Arab artist in Europe: resources and narratives}

TIPO DE TRABAJO: Comunicación.

PALABRAS CLAVE

Arte, poética, exilio, identidad, árabe.

KEY WORDS

Art, poetic, exile, identity, Arabic.

RESUMEN

En este estudio pretendemos profundizar en cómo la condición identitaria de una serie de artistas árabes de la diáspora, indefectiblemente marcada por la experiencia del exilio, ha influido en la construcción de sus respectivas estrategias narrativas y en el uso que hacen de la poética como instrumento con el cual tratar problemáticas como la migración, los conflictos identitarios y el racismo, entre otros. Los artistas que emplearemos como ejemplo son creadores arabo-descendientes y expatriados, voluntaria 0 involuntariamente. Nos referimos a creadores como Adel Abidin, Zineb Sedira, Mona Hatoum, Mounir El Fatmi, Zoulikha Bouabdellah y Taysir Batniji, Yto Barrada, Kader Attia, entre otros. Estos artistas manifiestan un claro compromiso social. Critican, reflexionan y transmiten una mirada diferente, que va más allá del lenguaje didáctico, lineal y comunicativo para analizar desde la distancia la realidad sociopolítica de sus países de origen, pero no dudan en hacer lo mismo con sus países de adopción.

\section{ABSTRACT}

In this study we intend to deepen in how the condition of a series of Arab artists of the diaspora, unfailingly marked by the exile experience, has influenced the construction of their narrative strategies and the use they make of poetics as an instrument dealing with problems such as migration, identity conflicts and racism, among others. The artists used as examples are Arabo-descendant and expatriate creators, voluntarily or involuntarily. We refer to creators such as Adel Abidin, Zineb Sedira, Mona Hatoum, Mounir El Fatmi, Zoulikha Bouabdellah and Taysir Batniji, Yto Barrada, Kader Attia, among others. These artists manifest a clear social commitment. They criticise, reflect and share a different point of view, beyond didactic, lineal and communicative language to analyze from afar the sociopolitical reality of their countries of origin, but do not hesitate to do the same with those of adoption.

\section{INTRODUCCIÓN}

Según Aristóteles la extensión poética del arte a menudo aporta al espectador una mirada más amplia de lo representado, si es suficientemente inteligente como para captarla. El arte según él es la comunicación más íntima del ser humano, no necesariamente se manifiesta en una disciplinariedad y/o en un lenguaje didáctico, sino aporta una perspectiva filosófica que se eleva de los aspectos formales propios de la técnica para ofrecer una comunicación horizontal con el espectador (Villar, 2013). 
En el caso de los artistas objeto de estudio, observamos concretamente ese distanciamiento del lenguaje próximo ${ }^{1}$, para proporcionar un enfoque diferente de los acontecimientos, construido desde la experiencia del desarraigo y la identidad compartida. A nuestro juicio la estrategia narrativa de los artistas objeto de estudio se asemeja a esa escena de Charlie Chaplin que cita Bertold Brecht, en la que aparece Chaplin llenando una maleta con ropa de manera desordenada y de repente la cierra de una vez. Tras ese acto radical comienza a cortar parte de sus prendas que sobresalen de la maleta en busca de un aparente orden (Brecht, 1994: 15).

La hipótesis que planteamos en este estudio parte precisamente de esta metáfora del desorden que manifiesta la experiencia del desarraigo, donde caben cuestiones como la identidad, el viaje, el exilio, la política, el género, la memoria o la nostalgia entre otras. A nuestro parecer, para analizar las estrategias narrativas de estos artistas y comprender los mecanismos discursivos que emplean en sus trabajos, se han de tener en consideración todos estos aspectos. No podemos definir un aspecto concreto sin referirnos a otro, tampoco podemos limitarnos a un estudio formal y/o histórico de sus obras, ya que la formalización estética se encuentra estrechamente sustentada sobre una coherencia discursiva de base, donde el objeto artístico se convierte en una simple representación material de una idea abstracta y desordenada.

Es por ello que marcamos como objetivo aportar una mirada distinta de la obra de estos creadores que va más allá de los aspectos formales y descriptivos, tratando de comprender cómo la distancia y la experiencia identitaria modelan sus estrategias narrativas.

Los artistas objeto de estudio son creadores de las tres últimas décadas que trabajan a partir del registro gráfico -fotografía, video, dibujo y estampa-, como recurso con el cual materializar sus propuestas artísticas.

\section{METODOLOGÍA}

En este sentido hemos realizado una selección previa de los artistas objeto de estudio y una recopilación de video-entrevistas, críticas realizadas en el contexto de exposiciones o catálogos, elementos que creemos que son primordiales para el desarrollo de este estudio.

- A nivel teórico partimos de tres referencias claves:

- La crítica que realiza Edward Said en su libro Orientalismo (2016) de los instrumentos de dominación y representación del otro desconocido.

- El ensayo Reflexiones sobre el exilio (2013), donde Said reúne durante un periodo de tres décadas un vasto trabajo intelectual que ofrece una lectura global de la experiencia del autor como intelectual comprometido que ha tenido que abandonar su país de origen forzado por las circunstancias.

- Cuando las imágenes toman posición (2008), un ensayo en el cual George Didi Huberman analiza las estrategias narrativas de la obra de Bertold Brecht, realizada durante el exilio.

- La estructura empleada en el desarrollo de este estudio se divide a su vez en tres apartados:

- La contextualización de la obra de los artistas objeto de estudio dentro del panorama artístico actual.

- El estudio de los diferentes mecanismos discursivos que emplean en sus obras.

- El análisis de los efectos de la experiencia del desarraigo en la manera con la cual estos creadores se dirigen hacia el espectador.

- Por último planteamos una serie de conclusiones construidas en base a los resultados obtenidos y respondiendo las cuestiones planteadas en la hipótesis.

\footnotetext{
${ }^{1}$ Referimos a la lectura inmediata que transmiten los medios de comunicación de los acontecimientos.
} 


\section{DESARROLLO}

\section{Hacia una nueva lectura de la historia del arte}

"[...] ya no se puede decir historia del arte, tenemos que decir las historias del arte, es decir, asumir decididamente una pluralidad. Hoy por hoy, estamos en 2016, ya no es lícito hablar de la historia, ya sea del arte o la historia en general. La historia del arte funciona como una especie de puzzle, hay una especie de imagen de conjunto, pero aún faltan muchísimos elementos. Mi generación de artistas, marroquíes o árabes o africanos o tercermundistas ha tratado de aportar algunas piezas para completar este puzzle". (El Fatmi, 2016)

Ese puzzle de la historia del arte al que se refiere el artista franco-marroquí Mounir El Fatmi, requiere hoy en día para ser completado una interacción horizontal efectiva, que vaya más allá de las aportaciones formales y estéticas de los artistas objeto de estudio en bienales y ferias de arte contemporáneo, poniendo en cuestión aquellos prejuicios establecidos como grandes verdades inamovibles como decía Bauman² refiriéndose a nuestros tiempos globalizados. (Bauman, 2004)

En efecto esta retórica de la otredad atañe también a la actividad creativa como define Said, poniendo de referencia a figuras de relevancia como Salman Rushdie y V.S. Naipaul. Según afirma:

[...] "a pesar de la omnipresente poder y alcance de estos vastos movimientos históricos, ha habido una gran resistencia a ellos, ya sea bajo la forma de los estridentes coros de "volvamos a las grandes obras de NUESTRA cultura", como en el racismo atroz que ofrece penosas muestras de sí mismo en los ataques a las culturas, tradiciones y pueblos no europeos que consideran que de algún modo no son dignos de atención o consideración seria" (Said, 2013: 17).

Si a día de hoy estamos poniendo en tela de juicio el eurocentrismo a través de este estudio y afirmando la necesidad del reconocimiento del otro es porque creemos que estamos en condiciones de superar ese imaginario creado sobre los árabes y esa relación de dominio que encontramos entre Flaubert y la cortesana egipcia, donde se observan dichos instrumentos de la fabricación del Otro, dominado y sumiso. La cortesana en este caso es una mujer árabe que no hablaba de sí misma y no expresaba sus opiniones. Según el análisis de Said, Flaubert es quien hablaba por ella "Él era extranjero, relativamente rico y hombre, y esos eran unos factores históricos de dominación que le permitían, no solo poseer a Kuchuk Hanem físicamente, isino hablar por ella y decir a sus lectores en qué sentido ella era típicamente oriental! "[...] (Said, 2016: 25).

En el terreno del arte contemporáneo, estos instrumentos de dominación aún persisten, se manifiestan a menudo como describe la artista visual franco argelina Zineb Sedira en etiquetas identitarias asignadas por comisarios e instituciones de promoción cultural (Gouldal, 2011: 216-217). Podemos observar claramente esta idea en la crítica que realiza el artista iraquí expatriado en Finlandia Adel Abidin, a través de su obra instalativa Blueprinte $(2013)^{3}$, donde emplea elementos como la arquitectura y el sonido para crear un dibujo interactivo a gran escala que transforma al espacio expositivo en una fábrica que define, asigna y empaqueta una identidad árabe determinada, hecha y concebida para el consumo global. Según describe Abidin en referencia a esta obra: [...] "Todas las identidades son creadas por el hombre y son comparables a la producción industrial. Como artista visual, me interesa cómo se gestionan y producen estas identidades"4 [...] (Maraya Art Centre, 2013)

Como podemos observar, la puesta en escena de la creación artística no occidental que hoy en día forma parte de la amalgama de un mundo globalizado y líquido que ha rezagado la visión utópica del otro, es una cuestión reciente. A pesar de la apertura que podemos percibir en los circuitos artísticos en la actualidad, aún persisten conceptos arraigados en la cultura occidental que señalan las diferencias y asocian a menudo al otro al exotismo.

Dichos instrumentos de encasillamiento, en el caso de los artistas árabes de la diáspora, condicionan sus miradas del mundo y afirman aún más sus diferencias. A pesar de formar parte de los circuitos artísticos más prestigiosos en sus países de adopción, no dejan de considerarse efectivos migrantes árabes. Ejemplo de ello es la explicación que hace El Fatmi, cuando dice "me considero un trabajador emigrado" (El Fatmi, 2016). Desarrolla dicho concepto en una microencuesta a pie de calle en París en 1999, en la cual plantea a la gente una pregunta que había leído en un libro del escritor argelino Mohammed Dib ${ }^{5}$. El libro se llama El árbol de los dichos y en él cuenta cómo en una conferencia le dijo Jacques Derrida: "El mundo está Ileno de extranjeros, ¿qquiénes son los otros?" (El Fatmi, 1999).

\footnotetext{
${ }^{2}$ Referimos al análisis que realiza Bauman del otro representado como un ser diferente y portador de incertidumbres.

${ }^{3}$ Vease el enlace: http://www.adelabidin.com/works/blueprint

${ }^{4}$ Texto traducido de: "all identities are man made and comparable to factory production. As a visual artist I am interested in how these identities are being managed and produced

${ }^{5}$ Vease el enlace: http://www.mounirfatmi.com/work-47-06.htm
} 


\section{La metáfora de la identidad}

En base a lo anterior, detectamos un desplazamiento de la obra de arte hacia el espectador, donde este es invitado a completar la información, activar sus sentidos y cuestionar sus propios prejuicios, estableciendo precisamente ese espacio de discusión que concibe al espectador como parte integral de la actividad artística y que de algún modo nos lleva a la reflexión que plantea la artista francoargelina Zoulikha Bouabdellah, cuando dice: [...] "considero a los artistas como personas que van al encuentro de los ciudadanos". (Bouabdellah, 2015: 215).

Un claro ejemplo de esta idea que estamos planteando es la exposición colaborativa L'Un et l'Autre, (2018)6 . La exposición fue el resultado de intercambios de perspectivas entre el artista franco-argelino Kader Attia y el conocido artista multidisciplinar y escritor francés Jean-Jacques Lebel, en la cual presentan dos instalaciones. La primera obra de Attia, aborda la fabricación del otro por parte del poder colonial como una entidad violenta y guerrera que nunca deja de inspirar miedo: el irracional, el salvaje, el terrorista. Por su parte la segunda obra instalativa de Lebel se refiere a la persistencia a lo largo de la historia de humillación, violación y tortura en los crímenes de guerra imperialistas. Según describe Joseph Nechvatal esta exposición presenta: [...] "un arreglo antropológico-artístico que

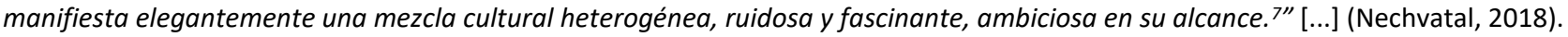

Parece evidente en el trabajo de estos artistas el uso de la metáfora como recurso narrativo para alejarse de la inmediatez que convierte al arte en un simple artefacto de consumo. Podemos observar dicha cuestión en la obra pictórica de aquel artista genio encerrado en su torre de marfil que critica Benjamin que aparta según él al espectador de la experiencia para sumergirse en cuestiones superficiales, propias de las formas ${ }^{8}$. Se trata por lo tanto de artistas que han podido despegarse de sus traumas para generar ese arte de pensar en la cabeza de los demás que formula Benjamin refiriéndose al movimiento Dada (Benjamin, 2015: 18).

En el video Dansons (2003) de Bouabdellah (Figura. 1), vemos precisamente esta idea que acabamos de explicar, de sumergir a los espectadores a través de la ficción en lo más íntimo de la experiencia vital.

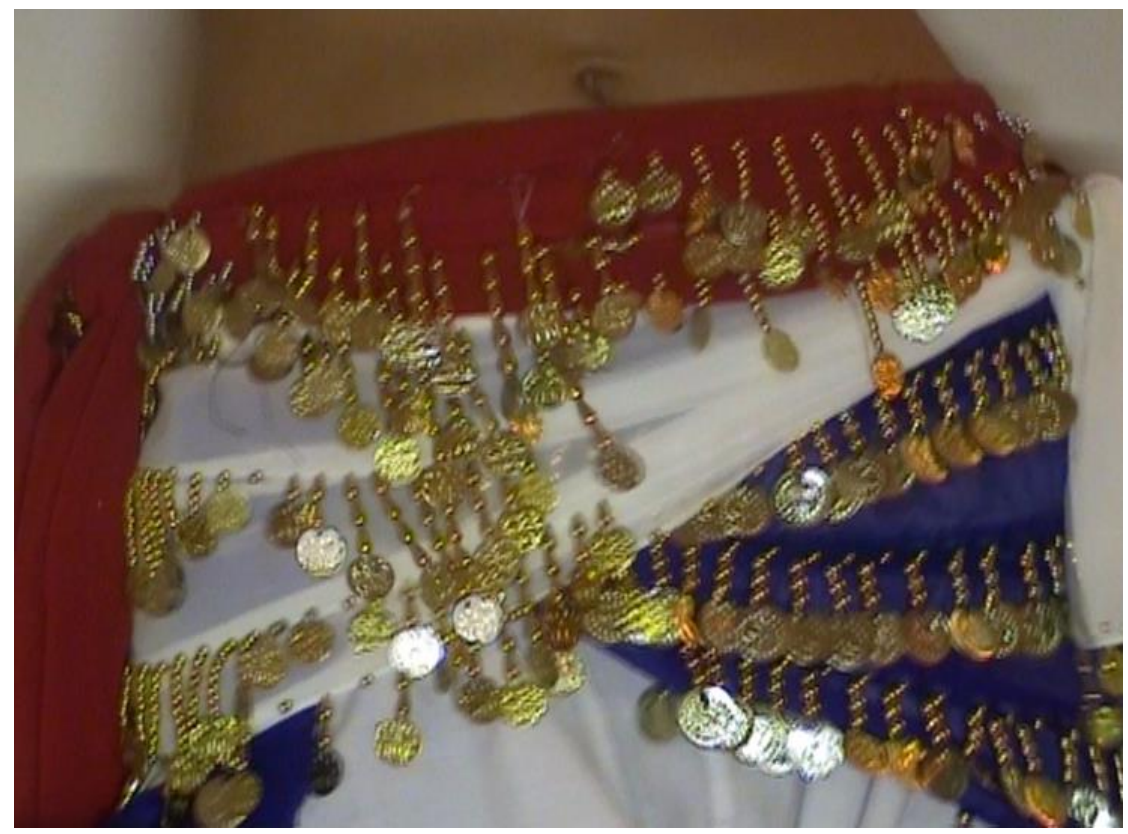

Figura 1: Vídeo de un canal. 00:05:55 min (Loop) de Zoulikha Bouabdellah,

"Dansons», 2003. Recuperado de: http://www.sabrinaamrani.com/galeria/artistas/zoulikha/work/dansons

\footnotetext{
${ }^{6}$ https://hyperallergic.com/441985/how-the-evil-other-was-conceptually-constructed-over-centuries/

${ }^{7}$ Texto traducido de: "anthropological-artistic arrangement that elegantly lays out a heterogeneous, noisy, and spellbinding cultural smorgasbord, ambitious in scope."

${ }^{8}$ Benjamin se refiere a los aspectos estético y materiales de la obra de arte.
} 
Bouabdellah confunde los arquetipos de las culturas francesa y argelina mediante una danza del vientre al ritmo de la Marsellesa, entremezclando el erotismo, las religiones, el feminismo y el simbolismo femenino en un lenguaje poético que aporta una perspectiva política. La artista en este video se autoanaliza mediante una reapropiación personal de los símbolos que forman parte integral de su identidad plural (cuerpo, danza, bandera, ritmo y la Marsellesa) y lucha firmemente contra el exotismo vinculado al cuerpo de las mujeres árabes.

\section{El distanciamiento y el compromiso político}

La poética en este caso se presenta como la culminación y la conclusión de toda una trayectoria vital, guerras, persecuciones, conflictos, pobreza, adoctrinamiento religioso, etc; proporcionando esa relación entre el arte y el enigma que formula Rafael Argullol, cuando dice "Y es que la poesía tiene el poder de evocar lo que puede ser, mientras la historia evoca solamente lo que es" (Argullol, 2011: 238).

En Common Vocabulary (2006) de Abidin (Figura, 2), se ve patente este uso de la poética como medio para transmitir mensajes que van más allá de la comunicación informativa de los acontecimientos, donde aparece una niña de siete años repitiendo las palabras de una voz en off, como si estuviera aprendiendo el vocabulario más común hoy en día en Irak. Las palabras y expresiones más repetidas son: muerte, ocupación, secuestro, genocidio, fosas comunes, escasez de agua, no hay electricidad. Estás palabras en boca de una niña adquieren una brutalidad extrema.

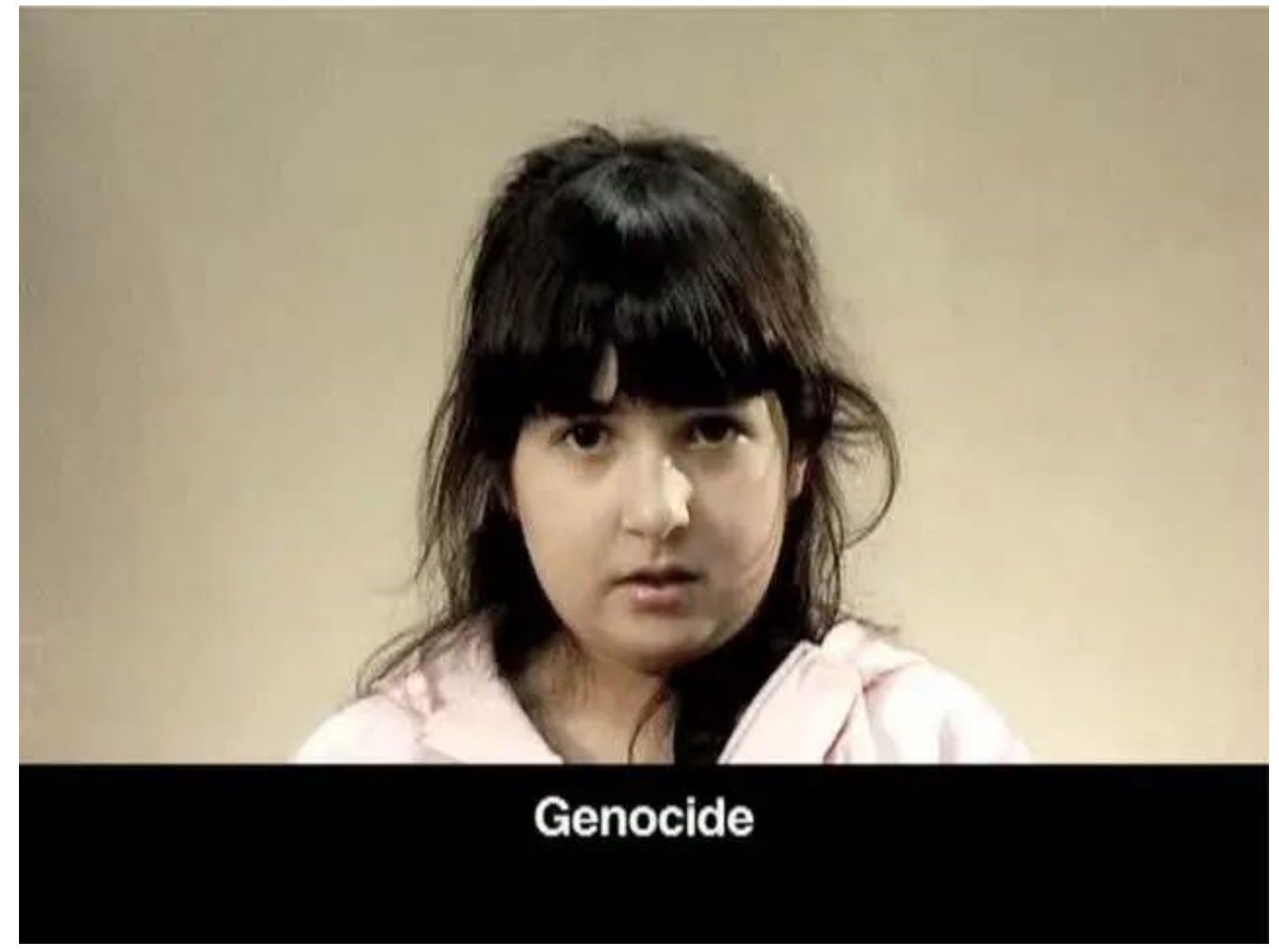

Figura 2: Video Installation. 00: 04:00 min (Loop) «Common Vocabulary», 2006 Recuperado de: http://www.adelabidin.com/works/common-vocabulary-2 . ( Adel Abidin

Abidin como podemos percibir a través de esta obra, se aleja de la violencia para representar sus huellas, transmitiendo una lectura abierta sobre la realidad sociopolítica de su país de origen que ofrece al espectador la posibilidad de interactuar con el contenido y participar activamente en la construcción de los significantes. 
Algo similar sucede en la instalación Arabesque ${ }^{9}$, creada por Attia en 2006 para la exposición Notre Histoire ${ }^{10}$ en el Palacio de Tokio. La pieza instalativa de Attia, consistió en una intervención en el espacio expositivo, creando una composición con motivos arquitectónicos arabescos que recuerdan a una pintura de Mondrian. Una inspección más cercana del trabajo revela como cientos de porras de la policía se habían hundido en el muro de hormigón de la pared.

La instalación fue creada tras las olas de violencia y una serie de disturbios que tuvieron lugar en París, evocando imágenes de ciudadanos estampados por poderes opresivos.

A este respecto conviene tener presente que la percepción de estos artistas no supone que su producción artística reproduzca necesariamente una narración lineal de una realidad determinada o de un conflicto social; todo lo contrario, más bien suele ocurrir que estos seleccionan o escogen partes de la realidad según el interés y la subjetividad personal. No obstante, creemos que el hecho de compartir historias vitales similares y un mismo sentimiento identitario repercute en la aparición de coincidencias en sus respectivas estrategias discursivas así como, en cierta medida, también en la estética de sus trabajos.

El uso de la poética en la obra de estos artistas es una manera de hablar constantemente de lo autobiográfico sin caer en el error de lo evidente. En Mother Tongue (2002) (Figura. 3), vemos como el uso de la lengua se transforma en un recurso narrativo con el cual Sedira trata de profundizar en su identidad compuesta y en la memoria. Gracias a ello se cuestionan las razones que empujaron a su familia a abandonar su país en plena Guerra Civil Argelina a través del uso de ficción.

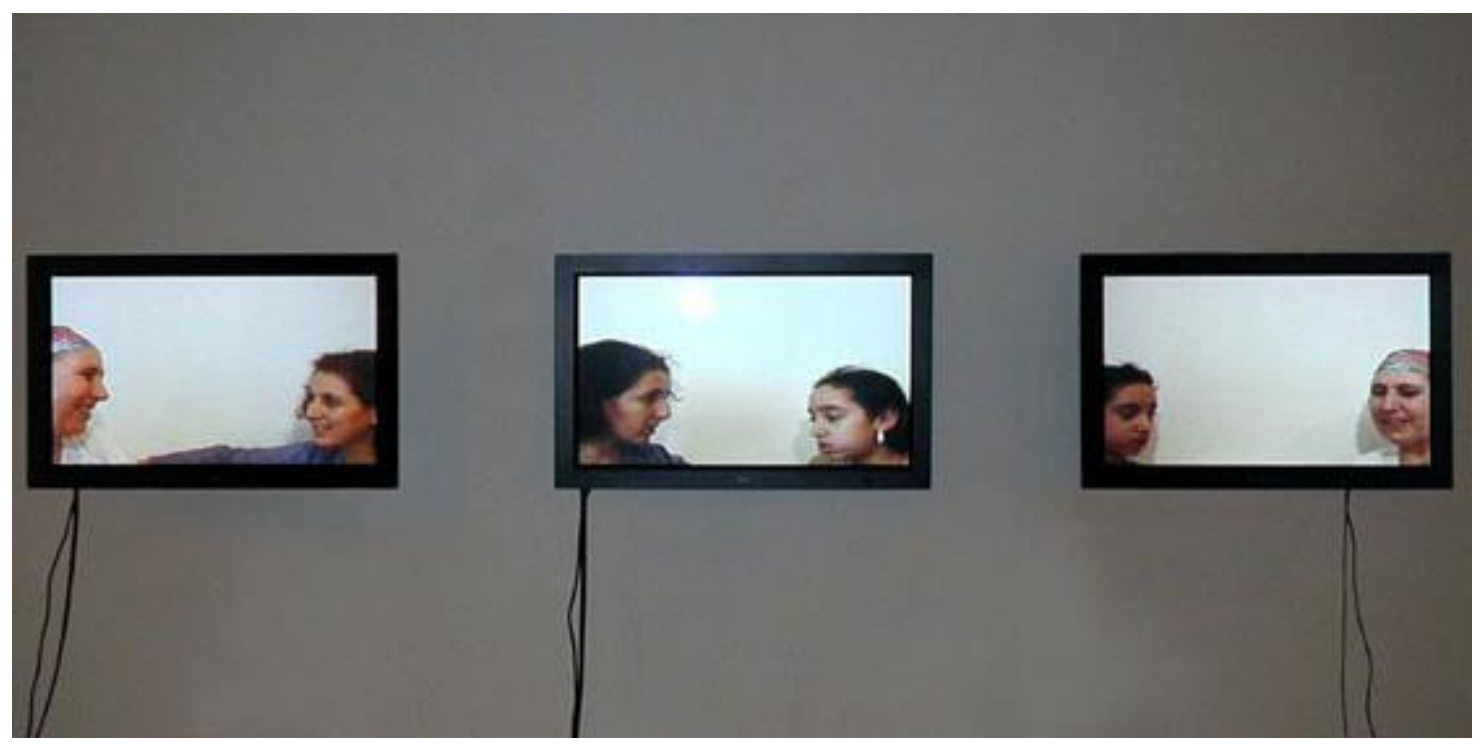

Figura 3: Instalación de 3 pantallas con auriculares, vídeo instalación 00:05:00 min (Loop) de Zineb Sedira, "Mother Tongue», 2002. Imagen recuperada de http://www.zinebsedira.com/video/mother-tongue-2002. C Zineb Sedira

Mother Tongue, consiste en un diálogo entre tres generaciones que hablan sobre la infancia en sus idiomas nativos: la artista en francés, su madre en árabe y su hija en inglés hasta que la comunicación se rompe entre la hija y la abuela.

\footnotetext{
${ }^{9}$ Vease el enlace: http://www.artnet.com/artists/kader-attia/arabesque-CDYyjxJ5crmAAZNNpF2D6w2

${ }^{10}$ La exposición Notre Histoire reunió obras de artistas emergentes de la escena francesa, formando un paisaje tridimensional que se construye en todos los espacios expositivos del Palacio de Tokio.
} 
Como podemos observar a través de esta obra, los artistas objeto de estudio mantienen esa dicotomía que describe el escritor alemán Lion Feuchtwanger como la grandeza y la miseria del exilio ${ }^{11}$ (Feuchtwanger, 1997). Una reflexión metafórica de la experiencia del exilio que según Didi-Huberman, a pesar del sufrimiento que supone, proporciona una mirada más sabia de las cosas.

\begin{abstract}
"Para saber hay que colocarse en dos espacios y en dos temporalidades a la vez. Hay que implicarse, aceptar entrar, afrontar, ir al meollo, no andar con rodeos, zanjar. También -porque zanjar lo implica- hay que apartarse violentamente en el conflicto o ligeramente, como el pintor que aparta del lienzo para saber cómo va su trabajo" (Didi-Huberman, 2008: 12).
\end{abstract}

\title{
CONCLUSIONES
}

En definitiva, podemos llegar a la misma conclusión de Didi Huberman, que afirma que el arte es una reflexión sobre el hombre y el contexto social en el cual se desarrolla y sobre el propio sujeto artista con su subjetividad y contradicciones. Didi Huberman parte del trabajo de Brecht como base con la cual analizar la relación entre la experiencia del exilio y la manera con la cual se construye el mensaje y se toman posiciones frente a los acontecimientos. Según afirma partiendo de un estudio exhaustivo de la obra de Brecht, la distancia permite una interpretación global de las cosas y genera precisamente la idea pilar de este estudio de la poética como estrategia narrativa del exilio (Didi-Huberman, 2008).

La labor de estos creadores de la diáspora, enfrentados a la desconfianza y el miedo a traicionar sus orígenes no consiste pues en formular doctrinas, ni tampoco encontrar soluciones, sino generar las preguntas correctas de la manera correcta cuando sea conveniente. Algo similar formula Said de la siguiente manera: "Ver a un poeta en el exilio en contraposición a leer la poesía es ver las antinomias del exilio personificadas y soportadas con una intensidad única" (Said, 2013: 181). Cuando Abidin presenta el video Common Vocabulary (2008) nos habla de su experiencia vital como artista que ha visto a su país entrar en un conflicto armado y ha tenido que abandonar su hogar, igual como lo hicieron muchos de sus compatriotas. Como podemos observar mediante las obras que hemos citado en este estudio, trabajar desde el exilio ofrece extrañeza y al mismo tiempo un aferramiento a una identidad fantasiada unida a una causa determinada.

La obra de estos artistas se presenta como la culminación de una trayectoria vital que busca compartir una serie de inquietudes con el espectador mediante una lectura codificada de los hechos, capaz de activar cuestiones emocionales que van más allá de la imagen desfigurada del Mundo Árabe que a menudo transmiten los medios de comunicación, contribuyendo enormemente a la visualización de una realidad compleja y con frecuencia difícil de mostrar.

Este estudio se enmarca dentro de una investigación predoctoral, donde estamos desarrollando un análisis específico sobre las estrategias narrativas de una serie de artistas árabes de la diáspora, que a nuestro juicio a día de hoy están poniendo en cuestión lo que entendemos como historia del arte contado desde Occidente, desmontando prejuicios y estereotipos asumidos desde la época colonial que asocian al otro desconocido como describe Said en su libro Orientalism (2015) a la violencia y el exotismo.

\section{FUENTES REFERENCIALES}

Abidin, A. (2006). Common Vocabulary, Recuperado de: http://www.adelabidin.com/works/common-vocabulary-2

Argullol, R. (2011). La estética y la construcción de una ética planetaria. En Arte y comunicación en el Mediterráneo. Quaderns de la Mediterránia, № 15. Barcelona: IEMed, pp. 238.

Benjamin, W. (2015). El autor como productor. Madrid: Casimiro libros, pp:18.

Bouabdellah, Z. (2003). Dansons. Recuperado de: http://www.sabrinaamrani.com/galeria/artistas/zoulikha/work/dansons

Bouabdellah, Z. (2015). Deseo de libertad. Awraq: Una década de transformaciones en el mundo árabe, no 15. Casa árabe Madrid, pp. 215.

Brecht, B. (1994). Narrativa Compleja 7, Diálogo de Refugiados. Madrid: Alianza, pp: 15.

\footnotetext{
${ }^{11}$ Feuchtwanger se refiere con este concepto a la situación de los escritores e intelectuales alemanes que se vieron obligados a abandonar Alemania después de que Hitler se convirtiera en canciller el 30 de enero de 1933.
} 
El registro gráfico en la obra del artista árabe expatriado en Europa: recursos y narrativas

IV Congreso INTERNACIONAL DE INVESTIGACIÓN EN ARTES VISUALES ANIAV 2019

IMAGEN [N] VISIBLE]

http://dx.doi.org/10.4995/ANIAV.2019.8954

Didi-Huberman, G. (2008). Cuando las imágenes toman posición. Madrid: Antonio Machado, pp. 12.

El Fatmi, M. (2016). Metrópolis - Mounir Fatmi, entrevistado por Maria Pallier [en línea]. 22 de may de 2016. [Marrakech] [consulta en linea: 20 de julio de 2018]. Disponible en: http://www.rtve.es/alacarta/videos/metropolis/metropolis-mounir-fatmi/3614401/

Feuchtwanger, L. (1994) Exil. Frankfurt: Fischer.

Gouldal, E. (2011). El concepto de hibridación en el arte contemporáneo argelino: expresiones de las paradojas de la globalización. En Arte y comunicación en el Mediterráneo. Quaderns de la Mediterránia, № 15, 216-217. Barcelona: IEMed.

Nechvatal, J. (2018). How the Evil "Other" Was Conceptually Constructed Over Centuries [consulta en linea: 18 de enero de 2019]. Disponible en: https://hyperallergic.com/441985/how-the-evil-other-was-conceptually-constructed-over-centuries/

Said, E. (2013). Reflexiones sobre el exilio y otros ensayos literarios y culturales. Barcelona: Debate, pp. 18.

Said, E. (2013). Reflexiones sobre el exilio y otros ensayos literarios y culturales. Barcelona: Debate, pp. 20.

Said, E. (2013). Reflexiones sobre el exilio y otros ensayos literarios y culturales. Barcelona: Debate, pp. 18.

Said, E. (2015). Orientalismo. Barcelona: Debolsillo Editorial, pp. 25.

Sedira, Z. (2002). Mother Tongue. Recuperado de http://www.zinebsedira.com/video/mother-tongue-2002

Villar, A. (2013). Poética. Madrid: Alianza. 